\title{
Costs and Treatment Pathways for Type 2 Diabetes in the UK: A Mastermind Cohort Study
}

Peter Eibich (1) - Amelia Green · Andrew T. Hattersley • Christopher Jennison •

Mike Lonergan · Ewan R. Pearson · Alastair M. Gray

Received: July 4, 2017 / Published online: September 6, 2017

(c) The Author(s) 2017. This article is an open access publication

\begin{abstract}
Introduction: Medication therapy for type 2 diabetes has become increasingly complex, and there are few reliable data on the current state of clinical practice. We report treatment pathways and associated costs of medication therapy for people with type 2 diabetes in the UK, their variability and changes over time.

Methods: Prescription and biomarker data for 7159 people with type 2 diabetes were extracted from the GoDARTS cohort study, covering the

Enhanced content To view enhanced content for this article go to http://www.medengine.com/Redeem/ F3FBF0601EBB561F.
\end{abstract}

Electronic supplementary material The online version of this article (doi:10.1007/s13300-017-0296-x) contains supplementary material, which is available to authorized users.

P. Eibich $(\bowtie) \cdot$ A. M. Gray

Health Economics Research Centre, Nuffield

Department of Population Health, University of Oxford, Oxford, UK

e-mail: peter.eibich@dph.ox.ac.uk

A. Green · C. Jennison

Department of Mathematical Sciences, University of Bath, Bath, UK

A. T. Hattersley

Medical School, University of Exeter, Exeter, UK

M. Lonergan · E. R. Pearson

Division of Molecular and Clinical Medicine, School

of Medicine, University of Dundee, Dundee, UK period 1989-2013. Average follow-up was 10 years. Individuals were prescribed on average 2.4 (SD: 1.2) drugs with average annual costs of $£ 241$. We calculated summary statistics for firstand second-line therapies. Linear regression models were used to estimate associations between therapy characteristics and baseline patient characteristics.

Results: Average time from diagnosis to first prescription was 3 years (SD: 4.0 years). Almost all first-line therapy (98\%) was monotherapy, with average annual cost of $£ 83$ (SD: $£ 204$ ) for 3.8 (SD: 3.5) years. Second-line therapy was initiated in $73 \%$ of all individuals, at an average annual cost of $£ 219$ (SD: $£ 305$ ). Therapies involving insulin were markedly more expensive than other common therapies. Baseline HbA1c was unrelated to future therapy costs, but higher average HbA1c levels over time were associated with higher costs.

Conclusions: Medication therapy has undergone substantial changes during the period covered in this study. For example, therapy is initiated earlier and is less expensive than in the past. The data provided in this study will prove useful for future modelling studies, e.g. of stratified treatment approaches.

Keywords: Costs; First-line therapy; Medication therapy; Second-line therapy; Therapy initiation; Type 2 diabetes; UK 


\section{INTRODUCTION}

Stratified treatment approaches for type 2 diabetes appear promising, since there is evidence of underlying heterogeneity in type 2 diabetes $[1,2]$ and many classes of oral anti-diabetes drugs with different mechanisms of action are available. Ongoing research efforts, such as the Mastermind study [3], aim to develop and evaluate stratified treatments. However, evaluating the benefits of stratified treatment over current clinical practice is made difficult by the increasingly complex sequencing and combinations of diabetes therapies under current clinical practice [4]. While guidelines suggest that metformin monotherapy should be used as the initial medication therapy, there is no clear guidance on the choice of other drug classes for later therapy lines or in persons where metformin is not tolerated or contraindicated $[5,6]$. Algorithms [6] and case studies [7] have been developed to support individualised treatment decisions. However, the current state of clinical practice is not clear, with surprisingly little reliable information. Previous health economic studies mainly focused on the costs of diabetes [8-13] or national prescription trends [14-18]. The few studies that have investigated the costs, timing and duration of individual therapies [19-21] have mostly focused on first-line therapy.

This article reports contemporary treatment pathways (i.e. the timing, duration and drug types prescribed in first- and second-line therapy) and associated costs for medication therapy of type 2 diabetes in the UK. We describe how treatment pathways and costs vary over time and across demographic subgroups.

\section{METHODS}

\section{Study Population}

We used data from the Genetics of Diabetes Audit and Research Tayside (GoDARTS) cohort study $[22,23]$. The study included individuals with physician-diagnosed type 2 diabetes in
Tayside and Fife, Scotland. Participants were recruited from primary care, secondary care diabetes clinics as well as primary care registers between 1998 and 2012 [24, 25]. Data were collected prospectively, and patient records were linked to the DARTS databases [26] to obtain retrospective data on prescriptions, biochemistry and phenotypes.

This study focused on prescriptions of anti-diabetes drugs for patients with type 2 diabetes. We excluded patients diagnosed before age 35 years, those who received insulin less than a year after diagnosis as well as individuals who received anti-diabetes drugs within 6 months of their first recorded prescription of any drug. Moreover, we excluded individuals with missing or inconsistent data on date of diagnosis. Finally, we excluded one patient who received gliquidone. A detailed description of our data cleaning and processing procedures is provided in the appendix.

Our final sample consisted of 19,269 observations for 7159 individuals. For this study, observations refer to prescription blocks, i.e. prescriptions of anti-diabetes drugs as well as repeat prescriptions of the same drug. For each of these blocks, we observed the date of the first and last prescription, the average daily dose and baseline demographic data. The costs were derived from the Prescription Cost Analysis England 2014 [27], and we linked data on drugs to average annual HbA1c levels from the GoDARTS study.

Table S.1 in the appendix shows the characteristics of the study cohort. Participants were recruited between 1998 and 2012. About half of the participants were diagnosed before 1998 . On average, participants had been diagnosed with type 2 diabetes 7 years before recruitment to the study and at an average age of 59.2 years. The data cover on average 10 years of follow-up, in which participants have been prescribed two different drugs on average with annual costs amounting to $£ 241$. Average body mass index (BMI) at the time of the first prescription was $31.5 \mathrm{~kg} / \mathrm{m}^{2}$, and $64 \%$ of the participants had smoked in the past. Average HbA1c levels at diagnosis were $60 \mathrm{mmol} / \mathrm{mol}(7.6 \%)$. 


\section{Statistical Methods}

We investigated frequency, timing, duration and costs of first- and second-line drug therapy as well as cost profiles over time and by different subgroups. In this analysis, we define a therapy line as any combination of drugs taken at the same time. A change of therapy occurs whenever an additional drug is prescribed or treatment with a drug is discontinued. Summary statistics are presented as means and standard deviations. Median values and interquartile ranges are presented in the appendix (Tables S.4 and S.5). R version 3.2 was used to process the data.

We conducted two-sample t-tests to test the significance of differences between subgroups. As a sensitivity analysis, we conducted Wilcoxon rank-sum tests to test whether observations from different subgroups were drawn from the same distribution. Linear regression models with robust standard errors were used to estimate associations between baseline characteristics and therapy characteristics for first- and second-line therapy. We conducted several sensitivity analyses to account for potential sources of bias. We estimated Tobit models censored at zero to account for the non-negativity of the outcome variables (appendix Table S.6). We estimated Cox and Weibull regression models in a survival analysis to account for censoring (appendix Table S.8). Finally, we re-estimated our models using only individuals with at least 5 and at most 15 years of follow-up to account for the limited duration of follow-up for individuals diagnosed from the year 2000 onwards (Appendix Table S.9). All statistical analyses were conducted in Stata version 14.1 .

\section{Ethics Compliance}

Approval for the GoDARTS study was granted by the East of Scotland Regional Ethics Committee $(09 / 21402 / 44)$. This article is based on previously conducted studies and does not involve any new studies of human or animal subjects performed by any of the authors.

\section{RESULTS}

\section{Descriptive Statistics for First- and Second-Line Therapy}

Table S.2 (Appendix) shows drug combinations for first-line therapy. In about $60 \%$ of cases metformin monotherapy was used as first-line therapy, as recommended in the guidelines, followed by sulphonylurea (34\%). These figures vary substantially over time. Among people diagnosed before the year 2000, 89\% received either metformin or sulphonylurea monotherapy, and $7 \%$ were prescribed insulin monotherapy. In contrast, among people diagnosed after the year 2000 (and after the introduction of guidelines recommending metformin as first-line therapy), $97 \%$ of all individuals were prescribed metformin or sulphonylurea monotherapy.

With the exception of insulin therapy, all common therapies cost less than $£ 1000$ for the entire duration of the drug therapy. Insulin is by far the most expensive first-line therapy with treatment costs of about $£ .975$ per year for the drug alone (excluding equipment such as test strips).

Only $7.3 \%$ of all individuals received their first prescription at the time of diagnosis. Average time to first-line therapy was 3 years, and this therapy was continued, on average, for 4 years. Table 1 provides these numbers for the whole sample as well as for different subgroups. The analysis by year of diagnosis indicates that the proportion of people commencing therapy at time of diagnosis has increased over time, while time to first-line drug therapy has fallen to 1.9 years for individuals diagnosed after the year 2000 compared with 4.5 years for those diagnosed before 2000 (difference $=-2.6$ years, $p<0.001$ ). However, it should be noted that fewer years of follow-up were available for people diagnosed in later years.

Annual therapy costs for first-line therapy were also lower for individuals diagnosed after $2000(£ 51.6$ vs. $£ 120.8$, difference $=-£ 69.2$, $p<0.001)$. We find that annual therapy costs were lower for obese people (BMI $\geq 30 \mathrm{~kg} / \mathrm{m}^{2}$ ) $(£ 68.5 \quad$ vs. $£ 88.1, \quad$ difference $=-£ 19.6$, 
Table 1 Duration and costs of first-line therapy

\begin{tabular}{|c|c|c|c|c|}
\hline & Therapy at diagnosis (\%) & Time to therapy (years) & Annual cost of therapy $(\boldsymbol{E})$ & Duration of therapy (years) \\
\hline Overall sample $(n=7159)$ & 7.25 & $3.05 \pm 4.02$ & $83.11 \pm 203.68$ & $3.81 \pm 3.55$ \\
\hline \multicolumn{5}{|l|}{ A. Gender } \\
\hline $\operatorname{Men}(n=3953)$ & 7.03 & $3.2 \pm 4.15$ & $78.59 \pm 191.58$ & $3.77 \pm 3.47$ \\
\hline Women $(n=3206)$ & 7.52 & $2.86 \pm 3.85$ & $88.68 \pm 217.57$ & $3.87 \pm 3.65$ \\
\hline \multicolumn{5}{|l|}{ B. Smoking status } \\
\hline Smoked $(n=4098)$ & 7.98 & $2.76 \pm 3.7$ & $68.25 \pm 155.93$ & $3.66 \pm 3.37$ \\
\hline \multicolumn{5}{|l|}{ C. BMI } \\
\hline $\mathrm{BMI}<30(n=2825)$ & 4.99 & $3.57 \pm 4.34$ & $88.08 \pm 225.99$ & $4.01 \pm 3.65$ \\
\hline $\mathrm{BMI} \geq 30(n=3362)$ & 6.37 & $2.76 \pm 3.47$ & $68.48 \pm 152.54$ & $3.52 \pm 3.09$ \\
\hline \multicolumn{5}{|l|}{ D. Year of diagnosis } \\
\hline Before $2000(n=3259)$ & 4.45 & $4.46 \pm 5.04$ & $120.82 \pm 279.46$ & $4.32 \pm 4.21$ \\
\hline $\begin{array}{l}\text { From } 2000 \text { onwards } \\
\qquad(n=3900)\end{array}$ & 9.59 & $1.86 \pm 2.31$ & $51.59 \pm 93.39$ & $3.39 \pm 2.82$ \\
\hline \multicolumn{5}{|l|}{ E. Age at diagnosis } \\
\hline$<50(n=1406)$ & 9.59 & $4.2 \pm 5.55$ & $141.57 \pm 310.87$ & $3.61 \pm 3.94$ \\
\hline $50-54(n=942)$ & 7.01 & $3.39 \pm 4.18$ & $100.74 \pm 240.71$ & $3.76 \pm 3.7$ \\
\hline $55-59(n=1209)$ & 6.70 & $3.11 \pm 3.77$ & $73.66 \pm 168.14$ & $3.64 \pm 3.31$ \\
\hline $60-64(n=1231)$ & 7.80 & $2.74 \pm 3.49$ & $68.04 \pm 165.87$ & $3.92 \pm 3.47$ \\
\hline $65-69(n=1098)$ & 8.56 & $2.54 \pm 3.17$ & $64.87 \pm 140.15$ & $3.92 \pm 3.59$ \\
\hline$\geq 70(n=1273)$ & 8.25 & $2.21 \pm 2.72$ & $44.77 \pm 85.9$ & $4.04 \pm 3.23$ \\
\hline \multicolumn{5}{|l|}{ F. Initial HbAlc levels } \\
\hline 1st quartile $(n=1496)$ & 4.48 & $4.43 \pm 4.31$ & $68.11 \pm 181.86$ & $4.06 \pm 3.42$ \\
\hline 2nd quartile $(n=1425)$ & 4.91 & $2.94 \pm 3.11$ & $50.25 \pm 97.64$ & $3.84 \pm 3.03$ \\
\hline 3rd quartile $(n=1438)$ & 6.82 & $1.92 \pm 2.77$ & $56.9 \pm 127.84$ & $3.64 \pm 3.03$ \\
\hline 4th quartile $(n=1453)$ & 14.18 & $1.18 \pm 2.5$ & $56.55 \pm 88.46$ & $3.18 \pm 3.18$ \\
\hline \multicolumn{5}{|l|}{ G. Average HbA1c levels } \\
\hline 1st quartile $(n=1453)$ & 6.13 & $3.45 \pm 3.99$ & $51.13 \pm 100.21$ & $4.95 \pm 3.8$ \\
\hline 2nd quartile $(n=1453)$ & 6.54 & $2.68 \pm 3.35$ & $48.08 \pm 82.44$ & $4.26 \pm 3.25$ \\
\hline 3rd quartile $(n=1453)$ & 8.33 & $2.41 \pm 3.31$ & $59.22 \pm 145.2$ & $3.22 \pm 2.62$ \\
\hline 4th quartile $(n=1453)$ & 9.36 & $1.99 \pm 3.05$ & $73.84 \pm 171.02$ & $2.3 \pm 2.17$ \\
\hline
\end{tabular}

Source: GoDARTS, Prescription Cost Analysis England 2014. Column 1 gives the percentage of people that received their first prescription at the time of their diagnosis. Initial HbAlc quartiles in mmol/mol: [16, 46); [46, 55); [55, 69); [69, 178). Average HbAlc quartiles in mmol/mol: [36, 53); [53, 58); $[58,65)$; [65, 112). Initial HbAlc quartiles in \%: [3.6, 6.4); [6.4, 7.2); [7.2, 8.5); [8.5, 18.4). Average HbAlc quartiles in \%: [5.4, 7.0); [7.0, 7.5); [7.5, $8.1) ;[8.1,12.4)$ 
Table 2 Duration and costs of second-line therapy

\begin{tabular}{|c|c|c|c|c|c|c|}
\hline & $\begin{array}{l}\text { Second-line } \\
\text { therapy } \\
\text { observed } \\
(\%)\end{array}$ & $\begin{array}{l}\text { Therapy } \\
\text { substitution } \\
\text { (\%) }\end{array}$ & $\begin{array}{l}\text { Gap } \\
\geq 90 \text { days } \\
(\%)\end{array}$ & $\begin{array}{l}\text { Gap between } \\
\text { 1st- and } \\
\text { 2nd-line } \\
\text { therapies (years) }\end{array}$ & $\begin{array}{l}\text { Duration } \\
\text { of therapy }\end{array}$ & $\begin{array}{l}\text { Annual cost } \\
\text { therapy }\end{array}$ \\
\hline Overall $(n=5254)$ & 73.39 & 15.32 & 7.74 & $1.71 \pm 2.29$ & $3.12 \pm 3.07$ & $186.53 \pm 264.51$ \\
\hline \multicolumn{7}{|l|}{ A. Gender } \\
\hline $\operatorname{Men}(n=2890)$ & 73.11 & 14.15 & 7.06 & $1.7 \pm 2.28$ & $3.15 \pm 2.99$ & $181.86 \pm 256.77$ \\
\hline Women $(n=2364)$ & 73.74 & 16.75 & 8.58 & $1.72 \pm 2.31$ & $3.08 \pm 3.17$ & $192.23 \pm 273.63$ \\
\hline \multicolumn{7}{|l|}{ B. Smoking status } \\
\hline Smoked $(n=3042)$ & 74.23 & 14.40 & 7.22 & $1.74 \pm 2.33$ & $3.11 \pm 3.03$ & $177.25 \pm 255.55$ \\
\hline \multicolumn{7}{|l|}{ C. BMI } \\
\hline $\mathrm{BMI}<30(n=1953)$ & 69.13 & 17.15 & 8.25 & $1.7 \pm 2.34$ & $3.06 \pm 3.05$ & $184.9 \pm 275.22$ \\
\hline $\mathrm{BMI} \geq 30 \quad(n=2468)$ & 73.41 & 12.56 & 5.98 & $1.33 \pm 1.87$ & $2.9 \pm 2.79$ & $185.36 \pm 248.29$ \\
\hline \multicolumn{7}{|l|}{ D. Year of diagnosis } \\
\hline $\begin{array}{l}1989-1999 \\
(n=2697)\end{array}$ & 82.76 & 18.28 & 10.83 & $1.94 \pm 2.57$ & $3.68 \pm 3.54$ & $198.8 \pm 286.84$ \\
\hline $\begin{array}{l}2000-2013 \\
(n=2557)\end{array}$ & 65.56 & 12.20 & 5.15 & $1.35 \pm 1.71$ & $2.52 \pm 2.34$ & $173.58 \pm 238.08$ \\
\hline \multicolumn{7}{|l|}{ E. Age at diagnosis } \\
\hline$<50(n=1185)$ & 84.28 & 16.37 & 10.81 & $1.97 \pm 2.09$ & $3 \pm 3.06$ & $231.96 \pm 308.9$ \\
\hline $50-54(n=759)$ & 80.57 & 11.86 & 5.94 & $1.57 \pm 2.26$ & $3.11 \pm 2.87$ & $205.06 \pm 282.76$ \\
\hline $55-59(n=924)$ & 76.43 & 14.50 & 8.11 & $1.94 \pm 2.71$ & $3.2 \pm 3.1$ & $168.37 \pm 218.25$ \\
\hline $60-64(n=917)$ & 74.49 & 15.59 & 7.55 & $1.5 \pm 2.28$ & $3.39 \pm 3.28$ & $174.44 \pm 261.84$ \\
\hline $65-69(n=765)$ & 69.67 & 14.77 & 6.83 & $1.65 \pm 2.27$ & $3.24 \pm 3.17$ & $169.16 \pm 241.9$ \\
\hline$\geq 70(n=704)$ & 55.30 & 18.61 & 6.28 & $1.46 \pm 2.17$ & $2.7 \pm 2.83$ & $148.5 \pm 232.77$ \\
\hline \multicolumn{7}{|l|}{ F. Initial HbAlc levels } \\
\hline 1st quartile $(n=1074)$ & 71.79 & 17.50 & 10.09 & $2.36 \pm 2.77$ & $3.11 \pm 3.12$ & $168.28 \pm 245.96$ \\
\hline $\begin{array}{l}\text { 2nd quartile } \\
(n=1024)\end{array}$ & 71.86 & 17.29 & 8.07 & $1.48 \pm 2.04$ & $2.87 \pm 2.84$ & $178.83 \pm 262.06$ \\
\hline $\begin{array}{l}\text { 3rd quartile } \\
(n=1180)\end{array}$ & 82.06 & 14.41 & 7.44 & $1.37 \pm 1.78$ & $3.1 \pm 2.92$ & $177.76 \pm 241$ \\
\hline $\begin{array}{l}\text { 4th quartile } \\
(n=1270)\end{array}$ & 87.41 & 9.29 & 5.23 & $1.52 \pm 2.14$ & $3.31 \pm 3.04$ & $161.13 \pm 222.71$ \\
\hline
\end{tabular}


Table 2 continued

$\begin{array}{llllll}\begin{array}{l}\text { Second-line } \\ \text { therapy }\end{array} & \begin{array}{l}\text { Therapy } \\ \text { substitution }\end{array} & \begin{array}{l}\text { Gap } \\ \mathbf{2 9 0} \text { days } \\ \text { observed }\end{array} & \begin{array}{l}\text { Gap between } \\ \text { 1st- and }\end{array} & \begin{array}{l}\text { Duration } \\ \text { of therapy }\end{array} & \begin{array}{l}\text { Annual cost } \\ \text { therapy }\end{array} \\ (\%) & (\%) & \begin{array}{l}\text { 2nd-line } \\ \text { therapies (years) }\end{array} & \\ \end{array}$

\begin{tabular}{|c|c|c|c|c|c|c|}
\hline \multicolumn{7}{|l|}{ G. Average HbAlc levels } \\
\hline \multicolumn{7}{|c|}{$\begin{array}{l}\text { U. Average HbAlc levels } \\
\text { 1st quartile }(n=715) \quad 49.21\end{array}$} \\
\hline $\begin{array}{l}\text { 2nd quartile } \\
(n=1103)\end{array}$ & 75.91 & 13.24 & 6.33 & $1.71 \pm 2.32$ & $3.58 \pm 3.3$ & $149.16 \pm 202.73$ \\
\hline $\begin{array}{l}3 \text { rd quartile } \\
(n=1336)\end{array}$ & 91.95 & 11.38 & 7.09 & $1.55 \pm 1.93$ & $3.34 \pm 3.04$ & $170.83 \pm 241.26$ \\
\hline $\begin{array}{l}\text { 4th quartile } \\
(n=1394)\end{array}$ & 95.94 & 12.70 & 8.47 & $1.34 \pm 1.52$ & $2.5 \pm 2.49$ & $191.91 \pm 261.83$ \\
\hline
\end{tabular}

Source: GoDARTS, Prescription Cost Analysis England 2014. Column 1 gives the percentage of individuals for whom a switch in therapy is observed. Column 2 shows the percentage of people for whom the 2 nd-line therapy consisted of a substitution of drugs instead of the addition of a new drug. Initial HbAlc quartiles in mmol/mol: $[16,46) ;[46,55) ;[55$, 69); [69, 178). Average HbAlc quartiles in mmol/mol: [36, 53); [53, 58); [58, 65); [65, 112). Initial HbAlc quartiles in \%: $[3.6,6.4) ;[6.4,7.2) ;[7.2,8.5) ;[8.5,18.4)$. Average HbAlc quartiles in \%: $[5.4,7.0)$; [7.0, 7.5); [7.5, 8.1); [8.1, 12.4)

$p<0.001)$. In addition, these people received their first prescription on average 10 months earlier than non-obese people.

First-line therapy was initiated earlier for older people (e.g. 2.21 years for those over 70 compared with 4.2 years for individuals below 50; difference $=1.99$ years, $p<0.001$ ), and annual therapy costs were lower for older individuals as well $(£ 44.77$ for those over 70 vs. $£ 141.57$ for those under 50, difference $=-£$.79.13, $p<0.001$ ).

Finally, higher HbA1c values (both initial as well as average values) were associated with earlier therapy initiation, and high average HbA1c values were associated with a shorter duration of first-line therapy.

Table S.3 in the Appendix presents data for second-line drug therapy. Only $15 \%$ of the individuals received a monotherapy as their second-line drug treatment. A combination of metformin and sulphonylurea was the single most common second-line therapy, accounting for $62 \%$ of all second-line therapies. The majority of second-line treatments were relatively inexpensive.
A summary for subgroups of the population is provided in Table 2 . Here, we note that in the later (2000-2013) time period more second-line therapies involved adding an additional drug rather than substituting a drug. This may reflect the larger number of therapy options available in later years. Again, we find that therapy costs decreased over time ( $£ 198.8$ vs. $£ 173.6$, difference $=£ 25.2, p<0.001)$, although the ranksum test indicates that the differences in distributions are not significant $(p=0.0593)$. In contrast to the results for first-line therapies, the costs for second-line therapies are approximately equal for obese and non-obese people; however, the rank-sum tests indicate statistically significant differences in the underlying distributions $(p<0.001)$. A higher age at diagnosis is associated with lower costs for second-line therapy (difference between people over 70 and those under $50=-£ 57.05$, $\mathrm{p}<0.001)$. Finally, higher average HbA1c values were associated with higher annual costs (difference between 1st and 4th quartile $=£ 50.38$, $p<0.05)$ and a shorter duration of second-line therapy (difference $=-0.39$ years, $p<0.001$ ). 
Table 3 Regression of therapy outcomes on baseline characteristics

\begin{tabular}{|c|c|c|c|c|c|}
\hline \multirow[t]{2}{*}{ Variable } & \multicolumn{3}{|l|}{ First-line therapy } & \multicolumn{2}{|c|}{ Second-line therapy } \\
\hline & Time to therapy & Duration & $\overline{\text { Cost per day }}$ & Duration & Cost per day \\
\hline \multicolumn{6}{|l|}{ Age at diagnosis (reference category: $<50$ ) } \\
\hline \multirow[t]{2}{*}{$50-54$} & $-152.446^{*}$ & 45.347 & -0.008 & -22.284 & 0.002 \\
\hline & $(63.006)$ & $(52.162)$ & $(0.023)$ & $(52.571)$ & $(0.039)$ \\
\hline \multirow[t]{2}{*}{$55-59$} & $-205.008^{* * *}$ & -15.278 & $-0.053^{* *}$ & 22.598 & $-0.094^{* *}$ \\
\hline & $(58.115)$ & $(48.195)$ & $(0.018)$ & $(51.838)$ & $(0.032)$ \\
\hline \multirow[t]{2}{*}{$60-64$} & $-316.749^{* * *}$ & 88.786 & $-0.049^{* *}$ & 70.109 & -0.061 \\
\hline & $(57.591)$ & $(51.290)$ & $(0.018)$ & $(54.678)$ & $(0.037)$ \\
\hline \multirow[t]{2}{*}{$64-69$} & $-394.032^{* * *}$ & -0.996 & $-0.051^{* *}$ & 2.438 & -0.052 \\
\hline & $(56.852)$ & $(53.088)$ & $(0.017)$ & $(57.118)$ & $(0.039)$ \\
\hline \multirow[t]{2}{*}{$>70$} & $-396.952^{* * *}$ & 82.913 & $-0.063^{* * *}$ & -87.313 & $-0.140^{* * *}$ \\
\hline & $(54.526)$ & $(52.676)$ & $(0.018)$ & $(56.638)$ & $(0.039)$ \\
\hline \multirow[t]{2}{*}{ BMI between 25.00 and $29.99 \mathrm{~kg} / \mathrm{m}^{2}$} & -126.735 & 16.983 & -0.012 & 98.779 & $-0.120^{* *}$ \\
\hline & $(68.544)$ & $(58.996)$ & $(0.021)$ & $(60.080)$ & $(0.045)$ \\
\hline \multirow[t]{2}{*}{ BMI between 30.00 and $39.99 \mathrm{~kg} / \mathrm{m}^{2}$} & $-273.037^{* * *}$ & -51.281 & -0.019 & 102.157 & $-0.099^{*}$ \\
\hline & $(66.671)$ & $(57.433)$ & $(0.021)$ & $(58.575)$ & $(0.045)$ \\
\hline \multirow[t]{2}{*}{ BMI over $40.00 \mathrm{~kg} / \mathrm{m}^{2}$} & $-533.993^{* * *}$ & -14.823 & -0.009 & -24.59 & 0.016 \\
\hline & $(76.372)$ & $(73.930)$ & $(0.027)$ & $(71.202)$ & $(0.056)$ \\
\hline \multirow[t]{2}{*}{ Women } & $-66.725^{*}$ & 34.295 & 0.011 & -17.542 & -0.013 \\
\hline & $(30.481)$ & $(31.351)$ & $(0.009)$ & $(33.481)$ & $(0.022)$ \\
\hline \multirow[t]{2}{*}{ Smoking at baseline } & $-76.338^{*}$ & $-114.040^{* * *}$ & 0.003 & 7.197 & 0.001 \\
\hline & $(32.655)$ & $(32.332)$ & $(0.010)$ & $(33.966)$ & $(0.023)$ \\
\hline \multirow[t]{2}{*}{ Diagnosis $>2000$} & $-793.356^{* * *}$ & $-376.393^{* * *}$ & $-0.052^{* * *}$ & $-447.346^{* * *}$ & 0.006 \\
\hline & $(35.997)$ & $(35.443)$ & $(0.010)$ & $(35.990)$ & $(0.022)$ \\
\hline \multicolumn{6}{|c|}{ Initial HbA1c levels (reference category: 1st quartile) } \\
\hline \multirow[t]{2}{*}{ 2nd quartile } & $-342.326^{* * *}$ & $89.083^{*}$ & $-0.036^{*}$ & 46.745 & 0.027 \\
\hline & $(47.524)$ & $(43.797)$ & $(0.015)$ & $(47.975)$ & $(0.033)$ \\
\hline \multirow[t]{2}{*}{ 3rd quartile } & $-710.038^{* * *}$ & $166.387^{* * *}$ & $-0.034^{*}$ & $177.645^{* * *}$ & 0.027 \\
\hline & $(47.305)$ & $(45.493)$ & $(0.016)$ & $(48.326)$ & $(0.032)$ \\
\hline \multirow[t]{2}{*}{ 4th quartile } & $-942.402^{* * *}$ & $171.061^{* * *}$ & $-0.034^{*}$ & $358.566^{* * *}$ & -0.052 \\
\hline & $(48.313)$ & $(48.820)$ & $(0.017)$ & $(50.468)$ & $(0.031)$ \\
\hline
\end{tabular}


Table 3 continued

\begin{tabular}{|c|c|c|c|c|c|}
\hline \multirow[t]{2}{*}{ Variable } & \multicolumn{3}{|l|}{ First-line therapy } & \multicolumn{2}{|c|}{ Second-line therapy } \\
\hline & Time to therapy & Duration & Cost per day & Duration & $\overline{\text { Cost per day }}$ \\
\hline \multicolumn{6}{|c|}{ Average HbA1c levels (reference category: 1st quartile) } \\
\hline \multirow[t]{2}{*}{ 2nd quartile } & $-163.530^{* * *}$ & $-298.665^{* * *}$ & -0.012 & 103.534 & -0.038 \\
\hline & $(43.709)$ & $(49.185)$ & $(0.009)$ & $(54.530)$ & $(0.033)$ \\
\hline \multirow[t]{2}{*}{ 3rd quartile } & $-271.994^{* * *}$ & $-734.805^{* * *}$ & 0.013 & -22.667 & 0.014 \\
\hline & $(46.616)$ & $(47.834)$ & $(0.014)$ & $(52.417)$ & $(0.034)$ \\
\hline \multirow[t]{2}{*}{ 4th quartile } & $-374.481^{* * *}$ & $-1074.575^{* * *}$ & $0.044^{* *}$ & $-327.883^{* * *}$ & 0.058 \\
\hline & $(48.544)$ & $(50.016)$ & $(0.014)$ & $(52.361)$ & $(0.037)$ \\
\hline \multirow[t]{2}{*}{ Constant } & $2722.145^{* * *}$ & $2042.405^{* * *}$ & $0.247^{* * *}$ & $1194.238^{* * *}$ & $0.606^{* * *}$ \\
\hline & $(104.222)$ & $(83.145)$ & $(0.034)$ & $(79.370)$ & $(0.059)$ \\
\hline$N$ & 5187 & 5187 & 5187 & 3929 & 3929 \\
\hline
\end{tabular}

Source: GoDARTS, Prescription Cost Analysis England 2014. Time to therapy and duration of therapy in days. Costs are given in $£$. Initial HbAlc quartiles in mmol/mol: [16, 46); [46, 55); [55, 69); [69, 178). Average HbAlc quartiles in $\mathrm{mmol} / \mathrm{mol}$ : [36, 53); [53, 58); [58, 65); [65, 112). Initial HbAlc quartiles in \%: [3.6, 6.4); [6.4, 7.2); [7.2, 8.5); [8.5, 18.4). Average HbA1c quartiles in \%: [5.4, 7.0); [7.0, 7.5); [7.5, 8.1); [8.1, 12.4). The table shows regression coefficients from a linear regression of therapy duration and costs on baseline characteristics. Robust standard errors are shown in parentheses. ${ }^{* * *} p<0.001 ;^{* *} p<0.01 ;^{*} p<0.05$

\section{Associations between Baseline Characteristics and Therapy Characteristics}

Table 3 shows the results of linear regressions exploring the association between baseline characteristics and the timing, duration and costs of first- and second-line therapies. Each column shows the results from one regression model. Since all covariates are binary indicators, the point estimates should be interpreted as differences from the specified reference group. The constant gives the average for the overall reference group. For example, the results in column 1 should be interpreted as follows: The average time to first-line therapy for a non-smoking normal-weight man diagnosed before age 50 and before the year 2000 with both low initial and average HbA1c values was 2722 days or 7.5 years. For older individuals first-line therapy is initiated earlier. For example, for individuals aged 70 and above, therapy is initiated 397 days earlier.
Overall, the results confirm that year of diagnosis is significantly associated with time to therapy, duration and costs. For people diagnosed after the year 2000, first-line therapy was initiated on average 793 days (2.2 years) earlier than for those diagnosed before 2000. While it is important to note that fewer years of follow-up are available for individuals diagnosed later, sensitivity analyses addressing differences in the length of follow-up confirm our conclusions (see Appendix, Table S.8). The duration of first-line therapy was on average 376 days shorter for people diagnosed after 2000 when compared with those diagnosed before the year 2000 , i.e. second-line therapy was initiated earlier. For second-line therapy, year of diagnosis was also significantly associated with a shorter therapy duration. The results also show that both higher initial and average HbA1c values are associated with earlier commencement of first-line therapy. For example, individuals within the third quartile of initial HbA1c values start medication therapy on 
average 710 days earlier than individuals within the first quartile, and for those within the fourth quartile therapy is initiated 942 days (2.6 years) earlier than for those in the first quartile. Interestingly, higher initial HbA1c values are associated with longer first-line therapy, while higher average HbA1c values are associated with shorter first-line therapy.

We also considered interaction effects between year of diagnosis and other baseline characteristics (sex, BMI and smoking status, see Table S.8 in the Appendix). The estimated interaction effects were insignificant in most models, with the exception of time to first-line therapy.

\section{Longitudinal Changes in Therapy Costs}

We also investigated longitudinal changes in costs of therapy over time. For each individual, we aggregated costs of all drugs prescribed in each year, as first-line, second-line or subsequent treatment, starting the first year at the date of the first observed prescription. The results are shown in Figs. 1 and 2 below.

The dots mark the average costs across all individuals in a given year, and lines show 95\% confidence intervals around the means. Figure 1 shows that therapy costs steadily increased over time from diagnosis, starting at less than $£ 100$ per year and increasing to slightly less than $£ 400$ per year at 10 years after the start of therapy. There were no major differences between males and females. In contrast, therapy costs were lower for obese compared to non-obese people for the first 3 years after first prescription, after which the pattern reversed. This is in line with the findings in Tables 1 and 2. Average annual therapy costs were generally lower for people diagnosed after the year 2000 .

Figure 2 shows the same data by age smoking status, age at diagnosis and initial as well as average HbA1c levels. Therapy costs for smoking and non-smoking individuals are very similar. A lower age at diagnosis is associated with higher annual costs across all age categories. Interestingly, the association between average HbA1c levels and costs per year seems stronger than the association between costs and initial
HbA1c levels. For initial HbA1c levels, only individuals within the fourth quartile incurred significantly higher costs than those in the other three categories. In contrast, cost patterns for all four quartiles of average HbA1c level show a diverging pattern. Annual costs in the 10 th year after therapy initiation are about $£ 600$ higher in the fourth quartile than in the first quartile. This finding is confirmed in Figure S.1 in the Appendix, where we plotted average annual costs over all years by HbA1c decile.

\section{DISCUSSION}

One of the main contributions of this article is to describe patterns of medication therapy for people with type 2 diabetes in the UK, including data on timing and costs of therapies and their associations with baseline characteristics of individuals. Desai et al. [19] and Boccuzzi et al. [20] provided similar data for the US, but they investigated first-line therapy and not second-line therapy.

Our data show that over the past 2 decades drug therapy has become increasingly complex. There were 16 different first-line therapies and 29 different second-line therapies recorded in the data. Most of these therapy lines were very similar in terms of duration and costs. Therapies involving insulin were among the most expensive treatments and cost on average more than $£ 1000$ over the course of $3-4$ years. This is in line with earlier findings reported by Rathmann et al. [16, 17] for Germany. Similarly, Bexelius et al. [28] reported that annual costs doubled after initiation of insulin therapy in a cohort of Swedish patients.

We also find that treatment pathways and costs have changed considerably over the past 2 decades: first-line therapy is initiated earlier than it was for people diagnosed before 2000, and individuals progress faster through therapy lines. This is in contrast to the findings of Strain et al. [29], who concluded that time to treatment intensification has not changed significantly since the 1990s. Interestingly, we also found that in the first 3 years after diagnosis annual therapy costs were lower for people diagnosed after the year 2000 than for people 


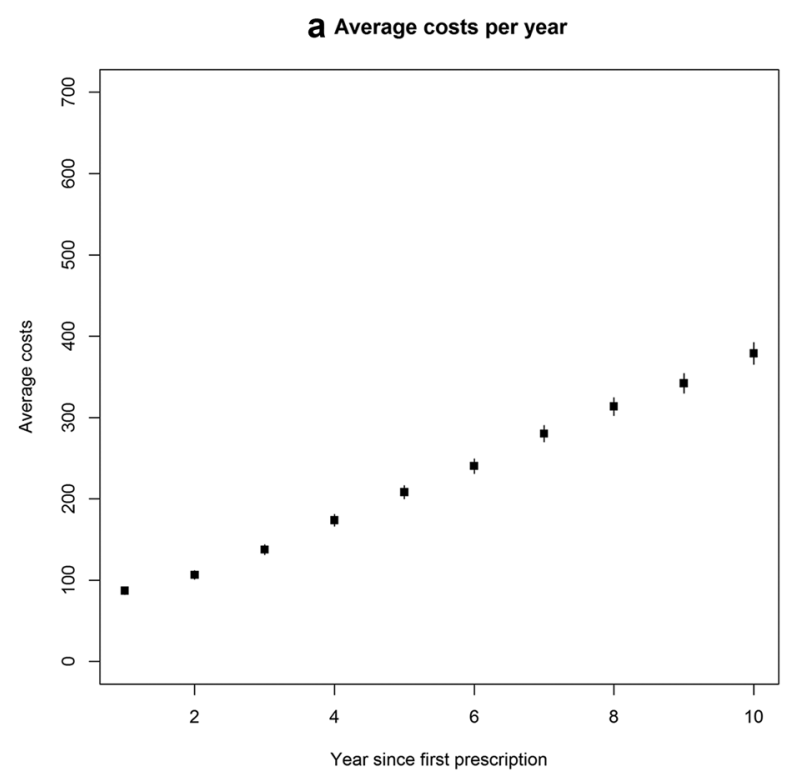

C Average costs per year by baseline BMI

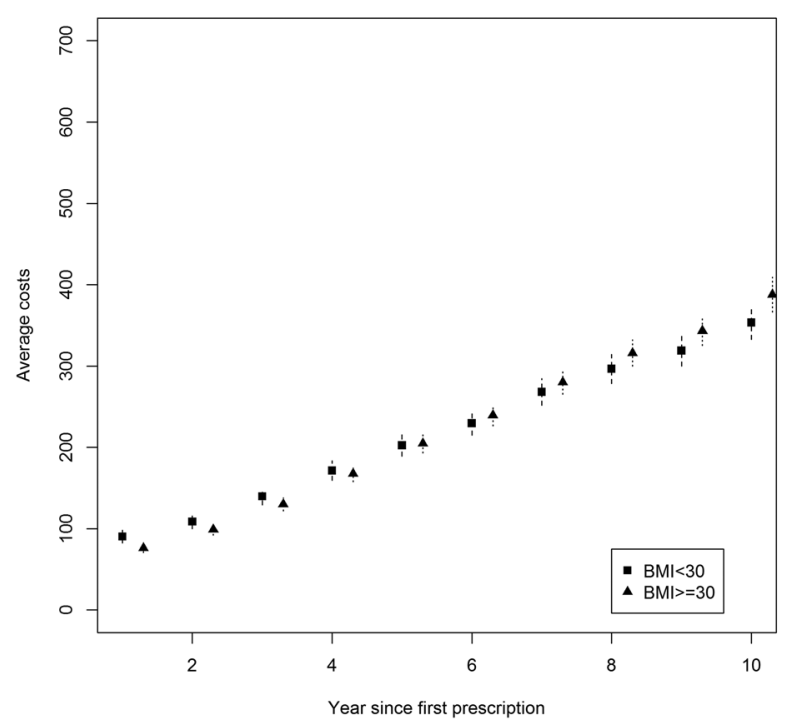

Fig. 1 The dots mark the average cost per year following the first observed prescription. The lines show 95\% confidence intervals. Measurements refer to completed years. Markers are offset to improve readability. The upper left panel shows the average profile for the whole sample. The upper right

diagnosed earlier. This likely reflects changing guidelines for first-line therapy. However, our results also indicated that considerable scope remains for earlier therapy initiation.

There were some differences across demographic groups, e.g. obese individuals had on average lower therapy costs during first-line b Average costs per year by sex

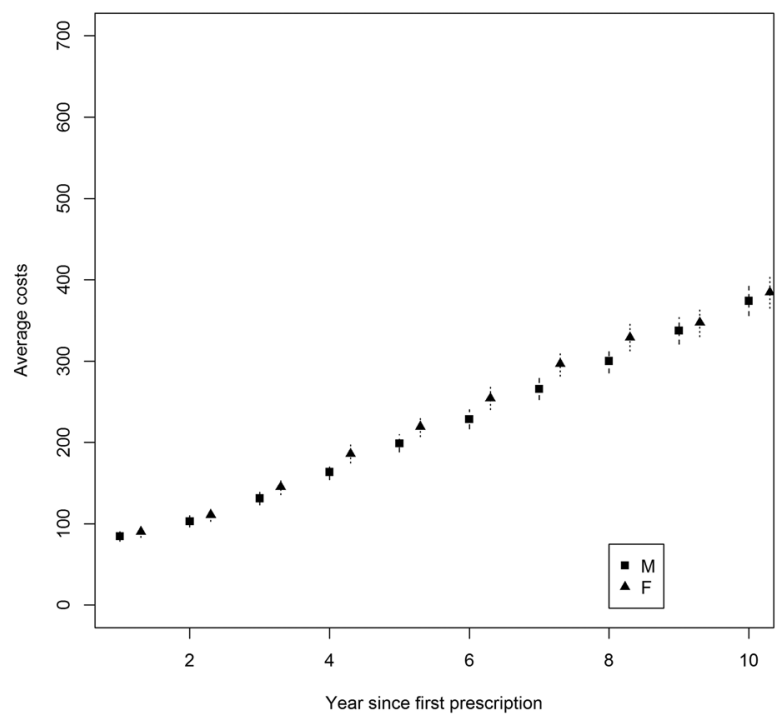

d Average costs per year by year of diagnosis

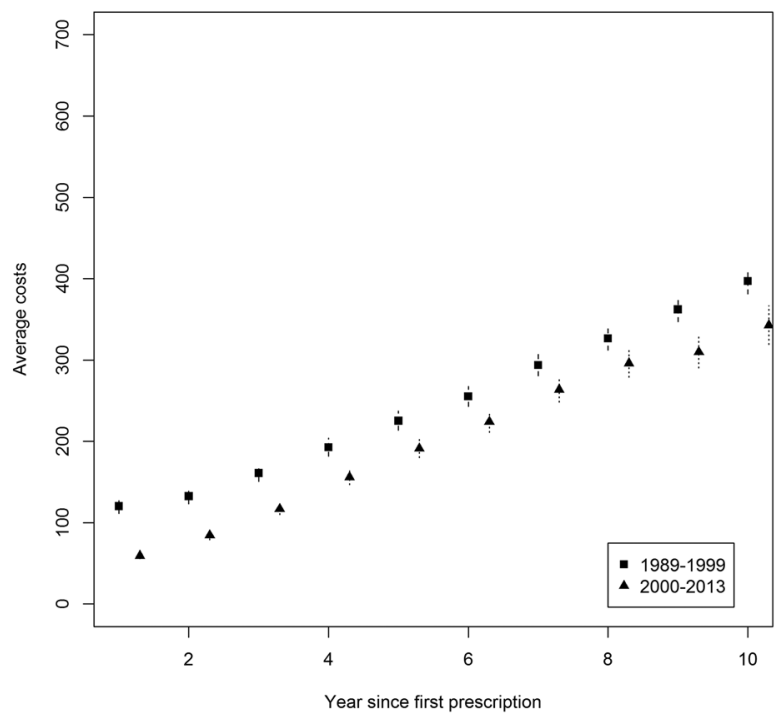

graph shows separate trends for males and females. The lower left figure shows data for people with a BMI above and below 30 , and the lower right figure shows separate graphs for people diagnosed before and after the year 2000. Source: GoDARTS, Prescription Cost Analysis England 2014

therapy than non-obese people. A possible explanation for this finding might be that therapy for obese individuals initially consists of weight loss and exercise alongside less expensive drugs, whereas non-obese people might be more likely to receive insulin early on. Indeed, the data showed that among people 

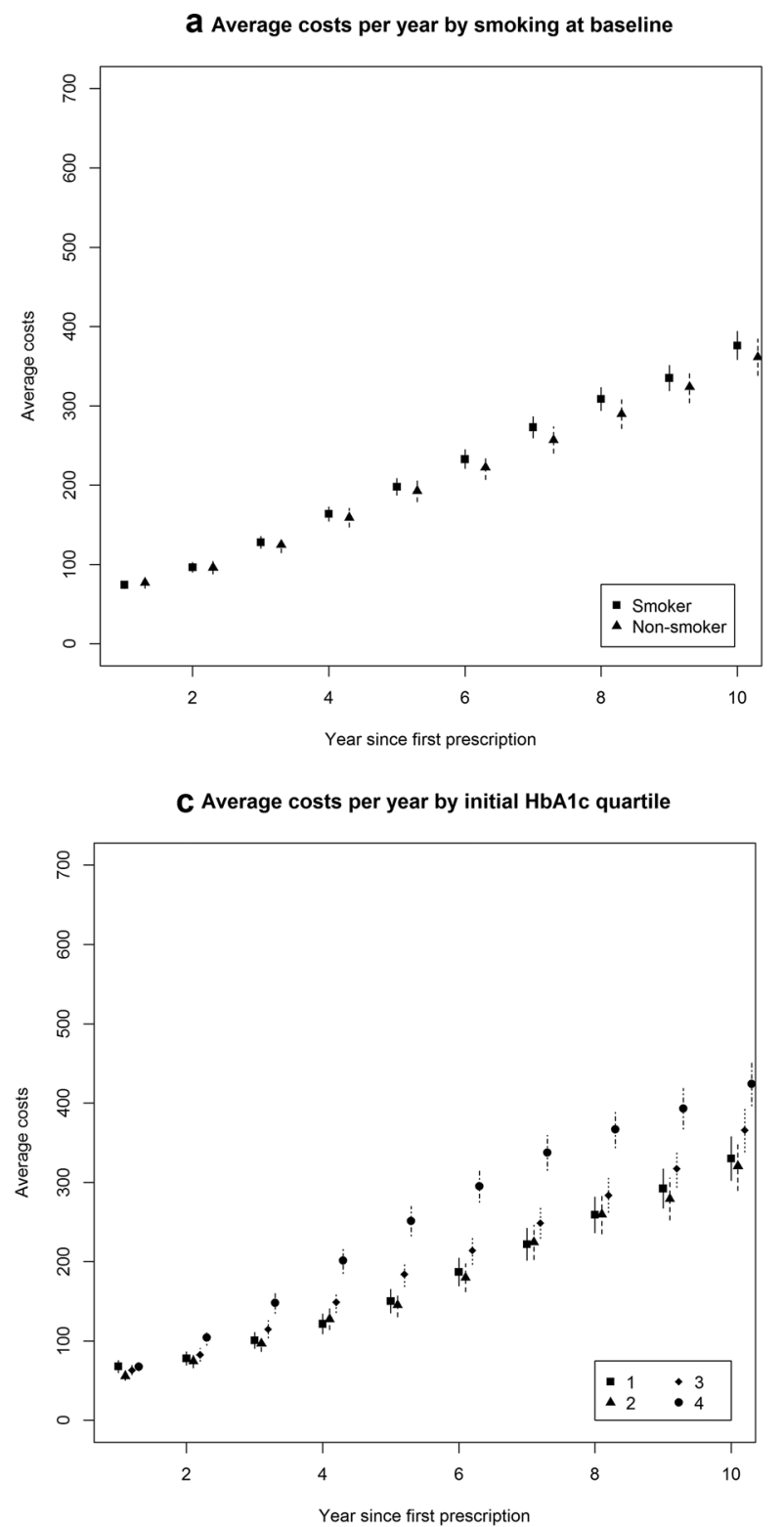

Fig. 2 The dots mark average cost per year following the first observed prescription. The lines show 95\% confidence intervals. Measurements refer to completed years. Markers are offset to improve readability. The upper left panel shows trends for smokers and non-smokers at baseline. The upper right graph shows separate trends by age at diagnosis. The lower left figure shows data by quartile of the initial HbAlc values, and the lower right figure shows data by quartile of

receiving insulin as first-line therapy (253 observations) only $35.9 \%$ had a BMI $\geq 30 \mathrm{~kg} /$ $\mathrm{m}^{2}$, whereas among those not receiving insulin monotherapy (6906 observations) 54.9\% were
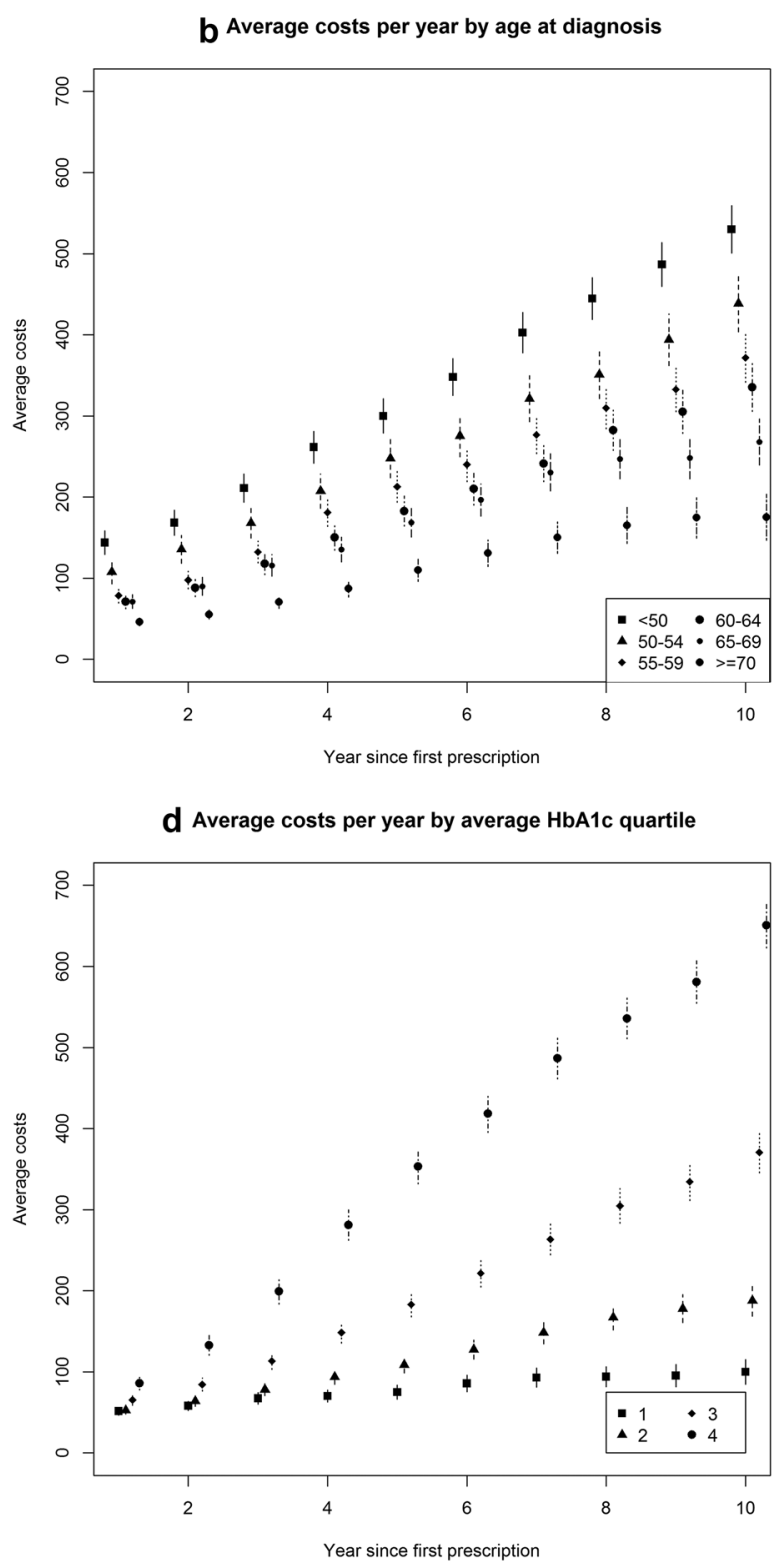

the average $\mathrm{HbA1c}$ values. Initial HbAlc quartiles in $\mathrm{mmol} / \mathrm{mol}$ : $[16,46) ;[46,55)$; [55, 69); [69, 178). Average HbAlc quartiles in mmol/mol: $[36,53)$; [53, 58); [58, 65); $[65,112)$. Initial HbAlc quartiles in \%: [3.6, 6.4); $[6.4,7.2) ;[7.2,8.5) ;[8.5,18.4)$. Average HbAlc quartiles in \%: $[5.4,7.0)$; $[7.0,7.5)$; $[7.5,8.1)$; [8.1, 12.4). Source: GoDARTS, Prescription Cost Analysis, England 2014

obese. The difference (19\%) was statistically significant $(p<0.001)$. However, this initial difference vanishes after 3 years (Fig. 1). Moreover, medication therapy is initiated earlier in 
obese people (Table 1), and therefore the lifetime costs of obese people could even be higher.

We also found that high average HbA1c levels over the period of our study are associated with up to four times higher costs than lower HbA1c levels. This is likely because individuals showing a poor response to their initial therapies have their doses intensified and move on to other drugs more rapidly than individuals showing a good response. While Porath et al. [30] reported that the impact of HbA1c on costs was limited, our findings are in line with Bennett et al. [31] and Fu et al. [32], who found that increasing HbA1c levels and the lack of a glycaemic response, respectively, were predictors of therapy initiation and escalation.

There are several limitations of our study. First, it is based on a sample drawn entirely from Tayside and Fife, Scotland, and so may not be representative of prescription patterns or of populations elsewhere, although there is no reason to think these are systematically different (apart from low representation of some ethnic groups). Second, the data cannot be used to accurately describe prescribing patterns and costs before the 1990s, since very few people in the cohort were diagnosed at that point. Similarly, the duration of follow-up in some of our analyses is necessarily limited. For example, our data do not include any prescriptions of SGLT-2 inhibitors. Nevertheless, our findings show that newer drugs (e.g. GLP-1 receptor agonists and DPP4-inhibitors) are rarely prescribed in first- or second-line therapy. We note also that individuals had to be alive at the time of their inclusion into the cohort, and consequently individuals with major adverse events shortly after diagnosis might be under-represented in the study. It is also possible that the estimates of our regression analysis are biased because of unobserved confounders (e.g. education, comorbidities, etc.). However, this study does not test any specific hypotheses, nor do we aim to study causal effects. Instead, the focus is on differences across easily identifiable subgroups of people with type 2 diabetes. Therefore, we are less concerned about confounding. We used linear regression models to study associations between baseline characteristics and therapy outcomes, since linear models offer an intuitive interpretation of the results. However, the results could be affected by a number of issues. Censoring of the data might mean that the recorded duration of first- and second-line therapy is underreported. We conducted a survival analysis to assess the sensitivity of our results and found that our conclusions hold. Moreover, our outcomes (costs and duration) are non-negative, and therefore the assumption of normally distributed standard errors in the linear regression model might not hold. We estimated Tobit regression models in a sensitivity analysis and concluded that our main findings are robust. Finally, our comparison of individuals diagnosed before the year 2000 and from the year 2000 onwards might be biased by the limited duration of follow-up for individuals in the latter group. We assessed the sensitivity of our results by restricting the sample to individuals with a minimum of 5 and a maximum of 15 years of follow-up. This did not affect our main conclusions.

The data reported in this study only include anti-diabetes drugs. While anti-diabetes drugs account for a small proportion of the overall healthcare expenditures attributable to diabetes [8], the costs of prescription medications (and anti-diabetes drugs in particular) are a major driver of increasing costs over time both in the population [13] and for individual people [9]. There are some limitations to the dosage and cost data in our study. Our data are based on prescription encashment rather than actual usage. This is particularly problematic for insulin, since individuals can modify the dose as part of their self-management. Moreover, our data on insulin costs only include the drug itself and not any other necessary equipment, e.g. test strips. Consequently, the data on the costs of insulin might be less accurate than for other drugs. However, we argue that these limitations most likely lead to an underestimation of the costs of insulin therapy. We used prescription cost data from 2014. On the one hand, this means that we do not observe changes in costs over time (e.g. changes in prescription patterns for different types of insulins). On the other hand, the figures reported in this study might be more relevant for future modelling studies, since they use current prices for drugs. Finally, 
we focused here on annualised HbA1c levels and average doses. Some therapy approaches could involve shorter-term fine-tuning of dose intensification and therapy changes, but understanding patterns of within-year changes will require more complex methods and data sets and are a task for future work.

\section{CONCLUSIONS}

Over the past 2 decades, medication therapy for type 2 diabetes has undergone substantial changes in the UK. Nevertheless, scope remains for earlier therapy initiation and intensification. The data presented in this study should prove useful for future modelling studies.

\section{ACKNOWLEDGEMENTS}

The authors gratefully acknowledge funding by the Medical Research Council (MRC) and the Association of the British Pharma Industry (ABPI) for "Mastermind" (MRC APBI STratification and Extreme Response Mechanism IN Diabetes-MASTERMIND. Grant Ref.: MRIK005707/1). ERP holds Wellcome Trust New Investigator award 102820/Z/13/Z. GoDARTS was funded by the Wellcome Trust as the Wellcome Trust Type 2 diabetes case control study. The funders were not involved in any way in the research reported in this article. All named authors meet the International Committee of Medical Journal Editors (ICMJE) criteria for authorship for this manuscript, take responsibility for the integrity of the work as a whole and have given final approval to the version to be published.

Disclosures. Peter Eibich, Amelia Green, Andrew T Hattersley, Christopher Jennison, Mike Lonergan, Ewan R Pearson and Alastair M Gray have nothing to disclose.

Compliance with Ethics Guidelines. Approval for the GoDARTS study was granted by the East of Scotland Regional Ethics Committee $(09 / 21402 / 44)$. This article did not involve any new studies of human or animal subjects performed by any of the authors.

Prior Presentation. An earlier version of the study was presented in abstract form at the Diabetes UK Professional Conference 2016, 2-4 March 2016, Glasgow, UK. The abstract was published in Diabetic Medicine. 2016 March 1, 33 (Suppl. 1): 185.

Data Availability. The data sets generated during and/or analysed during the current study are not publicly available because of data protection regulations but are available from the GoDARTS Scientific Committee (for the raw data) and the corresponding author (for statistical code) on reasonable request.

Open Access. This article is distributed under the terms of the Creative Commons Attribution-NonCommercial 4.0 International License (http://creativecommons.org/licenses/by-nc/ $4.0 /$ ), which permits any noncommercial use, distribution, and reproduction in any medium, provided you give appropriate credit to the original author(s) and the source, provide a link to the Creative Commons license, and indicate if changes were made.

\section{REFERENCES}

1. Hattersley AT, Pearson ER. Minireview: pharmacogenetics and beyond: the interaction of therapeutic response, beta-cell physiology, and genetics in diabetes. Endocrinology. 2006;147:2657-63. doi:10. 1210/en.2006-0152.

2. Pearson ERD. RD Lawrence lecture 2013. Stratified approaches to the management of diabetes. Diabet Med J Br Diabet Assoc. 2013;2014(31):393-8. doi:10.1111/dme.12391.

3. Lonergan M, Senn SJ, McNamee C, Daly AK, Sutton R, Hattersley A, et al. Defining drug response for stratified medicine. Drug Discov Today. 2017;22:173-9. doi:10.1016/j.drudis.2016.10.016.

4. Grant RW, Pirraglia PA, Meigs JB, Singer DE. Trends in complexity of diabetes care in the United States from 1991 to 2000. Arch Intern Med. 2004;164:1134-9. doi:10.1001/archinte.164.10. 1134. 
5. American Diabetes Association. Approaches to Glycemic Treatment. Diabetes Care. 2015;38:S41-8. doi:10.2337/dc15-S010.

6. National Institute for Health and Care Excellence. Type 2 diabetes in adults: management. NICE guideline NG28 2015. https://www.nice.org.uk/ guidance/ng28/chapter/1-Recommendations\#drugtreatment-2. Accessed 13 Apr 2016.

7. Bannister M, Berlanga J. Effective utilization of oral hypoglycemic agents to achieve individualized HbA1c targets in patients with type 2 diabetes mellitus. Diabetes Ther. 2016;7:387-99. doi:10. 1007/s13300-016-0188-5.

8. American Diabetes Association. Economic costs of diabetes in the U.S. in 2012. Diabetes Care. 2013;36:1033-46. doi:10.2337/dc12-2625.

9. Johnson JA, Pohar SL, Majumdar SR. Health care use and costs in the decade after identification of type 1 and type 2 diabetes a population-based study. Diabetes Care. 2006;29:2403-8. doi:10.2337/ dc06-0735.

10. Oliva J, Lobo F, Molina B, Monereo S. Direct health care costs of diabetic patients in Spain. Diabetes Care. 2004;27:2616-21. doi:10.2337/diacare.27.11. 2616.

11. Ozieh MN, Bishu KG, Dismuke CE, Egede LE. Trends in health care expenditure in U.S. adults with diabetes: 2002-2011. Diabetes Care. 2015;38:1844-51. doi:10.2337/dc15-0369.

12. Shrestha SS, Zhang P, Albright A, Imperatore G. Medical expenditures associated with diabetes among privately insured U.S. youth in 2007. Diabetes Care. 2011;34:1097-101. doi:10.2337/dc102177.

13. Zhuo X, Zhang P, Kahn HS, Bardenheier BH, Li R, Gregg EW. Change in medical spending attributable to diabetes: national data from 1987 to 2011. Diabetes Care. 2015;38:581-7. doi:10.2337/ dc14-1687.

14. Chang C-H, Jiang Y-D, Chung C-H, Ho L-T, Chuang L-M. National trends in anti-diabetic treatment in Taiwan, 2000-2009. J Formos Med Assoc Taiwan Yi Zhi. 2012;111:617-24. doi:10.1016/j.jfma.2012.09. 009.

15. Currie CJ, Peters JR, Evans M. Dispensing patterns and financial costs of glucose-lowering therapies in the UK from 2000 to 2008. Diabet Med. 2010;27:744-52. doi:10.1111/j.1464-5491.2009. 02849.x.

16. Rathmann W, Haastert B, Icks A, Giani G. Trends in outpatient prescription drug costs in diabetic patients in Germany, 1994-2004. Diabetes Care. 2007;30:848-53. doi:10.2337/dc06-2000.

17. Rathmann W, Haastert B, Roseman JM, Gries FA, Giani G. Prescription drug use and costs among diabetic patients in primary health care practices in Germany. Diabetes Care. 1998;21:389-97. doi:10. 2337/diacare.21.3.389.

18. Torre C, Guerreiro J, de Oliveira Martins S, Raposo JF, Martins AP, Leufkens H. Patterns of glucose lowering drugs utilization in Portugal and in the Netherlands. Trends over time. Prim Care Diabetes. 2015;9:482-9. doi:10.1016/j.pcd.2015.03.009.

19. Desai NR, Shrank WH, Fischer MA, Avorn J, Liberman JN, Schneeweiss S, et al. Patterns of medication initiation in newly diagnosed diabetes mellitus: quality and cost implications. Am J Med. 2012;125:302.e1-7. doi:10.1016/j.amjmed.2011.07. 033.

20. Boccuzzi SJ, Wogen J, Fox J, Sung JCY, Shah AB, Kim J. Utilization of oral hypoglycemic agents in a drug-insured U.S. population. Diabetes Care. 2001;24:1411-5. doi:10.2337/diacare.24.8.1411.

21. Fu AZ, Qiu Y, Davies MJ, Engel SS. Initial sulfonylurea use and subsequent insulin therapy in older subjects with type 2 diabetes mellitus. Diabetes Ther. 2012;3:12. doi:10.1007/s13300-012-0012-9.

22. GoDARTS and UKPDS Diabetes Pharmacogenetics Study Group, Wellcome Trust Case Control Consortium 2, Zhou K, Bellenguez C, Spencer CCA, Bennett AJ, et al. Common variants near ATM are associated with glycemic response to metformin in type 2 diabetes. Nat Genet. 2011;43:117-20. doi:10. 1038/ng.735.

23. Zhou K, Donnelly L, Burch L, Tavendale R, Doney ASF, Leese $G$, et al. Loss-of-function CYP2C9 variants improve therapeutic response to sulfonylureas in type 2 diabetes: a Go-DARTS study. Clin Pharmacol Ther. 2010;87:52-6. doi:10.1038/clpt.2009. 176.

24. Pearson ER, Donnelly LA, Kimber C, Whitley A, Doney ASF, McCarthy MI, et al. Variation in TCF7L2 influences therapeutic response to sulfonylureas: a GoDARTs study. Diabetes. 2007;56:2178-82. doi:10.2337/db07-0440.

25. Kimber CH, Doney ASF, Pearson ER, McCarthy MI, Hattersley AT, Leese GP, et al. TCF7L2 in the Go-DARTS study: evidence for a gene dose effect on both diabetes susceptibility and control of glucose levels. Diabetologia. 2007;50:1186-91. doi:10.1007/ s00125-007-0661-9.

26. Morris AD, Boyle DI, MacAlpine R, Emslie-Smith A, Jung RT, Newton RW, et al. The diabetes audit and 
research in Tayside Scotland (darts) study: electronic record linkage to create a diabetes register. BMJ. 1997;315:524-8. doi:10.1136/bmj.315.7107. 524.

27. Health and Social Care Informatio Centre. Prescription cost analysis England 2014 2015. http:// content.digital.nhs.uk/catalogue/PUB17274. Accessed 22 Nov 2016.

28. Bexelius C, Lundberg J, Wang X, Berg J, Hjelm H. Annual medical costs of Swedish patients with type 2 diabetes before and after insulin initiation. Diabetes Ther. 2013;4:363-74. doi:10.1007/s13300013-0035-x.

29. Strain WD, Blüher M, Paldánius P. Clinical inertia in individualising care for diabetes: is there time to do more in type 2 diabetes? Diabetes Ther. 2014;5:347-54. doi:10.1007/s13300-014-0077-8.
30. Porath A, Fund N, Maor Y. Costs of managing patients with diabetes in a large health maintenance organization in israel: a retrospective cohort study. Diabetes Ther. 2017;8:167-76. doi:10.1007/ s13300-016-0212-9.

31. Bennett $\mathrm{H}$, McEwan P, Bergenheim $\mathrm{K}$, Gordon J. Assessment of unmet clinical need in type 2 diabetic patients on conventional therapy in the UK. Diabetes Ther. 2014;5:567-78. doi:10.1007/s13300014-0079-6.

32. Fu H, Cao D, Boye KS, Curtis B, Schuster DL, Kendall DM, et al. Early glycemic response predicts achievement of subsequent treatment targets in the treatment of type 2 diabetes: a post hoc analysis. Diabetes Ther. 2015;6:317-28. doi:10.1007/s13300015-0119-x. 